\title{
Evaluation of a charity-led secondary breast cancer support day: a model of survivorship care
}

\author{
Barbara S Baker $^{1}$, Jean Marshall ${ }^{2}$ and Caroline J Hoffman ${ }^{1}$ \\ ${ }^{1}$ Breast Cancer Haven, Dowgate Hill House, 14-16 Dowgate Hill, London EC4R 2SU, UK \\ ${ }^{2}$ Breast Cancer Haven, 4-5 The Gateway West, East Street, Leeds LS9 8DA, UK
}

\section{Abstract}

It has been estimated that there are 36,000 women living with secondary breast cancer in the UK. Many feel isolated and unsupported, their information needs unmet and unaware of available support services such as palliative care or support groups that could help to improve their quality of life.

To try to address these needs, a monthly support day was established in 2014 by the national UK breast cancer charity Breast Cancer Haven $(\mathrm{BCH})$ at their Yorkshire centre. The support day provides an opportunity for personal introductions and discussion with other people with secondary breast cancer, to obtain information about breast cancerrelated topics of their choice, to eat a healthy lunch and to experience a visualisation/ relaxation session. To evaluate how helpful this support day was to its participants, they were asked to complete a feedback form at the end of the day. A total of 171 forms were completed from 26 support days during the period February 2014-July 2018.

Participants stated that they found the support day helpful, relaxing, informative, supportive and enjoyable. All except two felt it met their needs and expectations and the majority found the length of the day just right. The personal introduction and discussion session were most frequently cited as the most useful part of the day, with the majority of participants ( $N=144,96.7 \%)$ rating it as very or moderately helpful.

These findings show that the $\mathrm{BCH}$ support day, developed to address the needs of people with secondary breast cancer, is a model of survivorship care that can have a positive impact on their lives.

Keywords: secondary breast cancer, support, survivorship, model of care

\section{Introduction}

Secondary breast cancer (also known as metastatic or stage four) occurs when breast cancer cells spread to other parts of the body such as the bone, brain, liver or lungs. It is not curable, but treatment can prolong survival. Median survival is around 3-4 years [1], but, depending upon site and response to treatment, some people live for many years and others just a few months after diagnosis.

Correspondence to: Barbara S Baker Email: barbara.baker@breastcancerhaven.org.uk

ecancer 2019, 13:991

https://doi.org/10.3332/ecancer.2019.991

Published: $12 / 12 / 2019$

Received: 01/05/2019

Publication costs for this article were supported by ecancer (UK Charity number 1176307).

Copyright: (c) the authors; licensee ecancermedicalscience. This is an Open Access article distributed under the terms of the Creative Commons Attribution License (http:// creativecommons.org/licenses/by/3.0), which permits unrestricted use, distribution, and reproduction in any medium, provided the original work is properly cited. 
It has been estimated that there are 36,000 women living with secondary breast cancer in the UK [2], and each year, around 11,400 women die from the disease [3]. However, as a result of inadequate data collection by many NHS Trusts, there is no accurate, up-to-date figure of the number of people diagnosed with secondary breast cancer in the UK [4]. Furthermore, people living with the disease feel the care they receive is inferior to that of people with primary breast cancer, and many feel isolated, unsupported and uncared for as a result [5]. In addition, they report that their information needs are not being met and that they are not being consistently signposted to available services such as palliative care or support groups that could improve their quality of life [5].

Breast Cancer Haven (BCH) is a national UK breast cancer charity supporting people through the physical and emotional experience of primary and secondary breast cancer. BCH provides free in-depth personalised programmes of psychological support, help with treatment side effects and supported self-management activities in five community-based centres located in London, Hereford, Yorkshire, Wessex and the West Midlands, two hospital breast units in London and Worcester, plus support days across the country. The charity has helped people live well with and beyond breast cancer since February 2000.

The $\mathrm{BCH}$ support programme, based on a model of integrated cancer care, has been developed over 20 years by the charity's experienced clinical team. It incorporates different forms of emotional and psycho-educational support as well as the use of complementary therapies to support physical symptoms. Regular service evaluations have been carried out to monitor its effectiveness [6, 7]. The programme consists of an initial 1-hour consultation with an experienced $\mathrm{BCH}$ healthcare professional to assess each person's needs and to mutually agree on an appropriate therapy plan, followed by up to 10 hours of free individual one-to-one therapies. After 6 hours of therapy, each person's treatment plan is reviewed with a $\mathrm{BCH}$ healthcare professional to monitor the effectiveness of the therapies.

Having received support from the charity after a primary diagnosis of breast cancer, people who later develop secondary tumours are offered a second support programme of therapies to help them with their symptoms and treatment side effects. In addition to their personalised support programme, a monthly support day tailored to address their specific needs has been established and evaluated at the BCH centre in Leeds, Yorkshire, since 2014. The support day provides an opportunity for personal introductions and discussion with other people in a similar situation, to obtain information about breast cancer-related topics of their choice, to eat a healthy lunch and to experience a visualisation/relaxation/meditation session. To evaluate how helpful this support day was to its participants, they were asked to complete a feedback form at the end of the day, the findings of which are reported here.

\section{Methods}

A service evaluation was carried out on a sample of people with secondary breast cancer who had attended at least one of the monthly support days developed specifically for them at the $\mathrm{BCH}$, Yorkshire centre. All people receiving help from $\mathrm{BCH}$ have given their consent, on registration, to be contacted for feedback about the charity's treatment programmes.

\section{Participants}

Participants were people with secondary breast cancer from Leeds, Halifax, Huddersfield, York, Wakefield and Bradford who had attended the $\mathrm{BCH}$, Yorkshire centre in Leeds. Their ages ranged from forties to late seventies with varying levels of mobility and general health.

An email or letter was sent to all the people with secondary breast cancer on the centre's visitor list (approximately 60) 2 weeks before each support day inviting them to attend. The numbers attending each support day averaged around 10-15.

\section{Secondary breast cancer support day programme}

The secondary breast cancer support days are organised from $11 \mathrm{am}$ to $3 \mathrm{pm}$, including a healthy lunch dividing the day into morning and afternoon sessions. Participants can attend as much or as little of the day as they like, which may be determined by, for example, their level of fatigue. 


\section{Morning session}

\section{Personal introductions and discussion}

This 1-hour session is facilitated by an experienced therapist and group facilitator who ensures that everyone has a chance to speak if they want to and that the group feel that they are driving the content of the discussion. The aim is to provide a safe environment in which group members feel able to express themselves freely and easily while receiving support from the therapist and other group members. New members are invited to introduce themselves to the group, if they wish, by saying as little or as much as they want to about themselves.

One of the main issues that are addressed within this session is the death of any of the members since the previous meeting. This involves, first, acknowledging when someone has died and allowing a short period of silence to think about the person and their family. Group members are then invited to speak about what the deceased person meant to them and to say goodbye, if they wish to do so. Group members who were friends of the person may also have attended the funeral and want to share that experience with the group. There is also a 'memory book' for people to express their thoughts in writing. If someone is attending for the first time in this situation, the therapist explains the aforementioned process to them so they know what to expect and can choose to join the group after the session if they so wish.

The members are encouraged to feedback to the therapist their views on how this sensitive issue is dealt with within the group to ensure that it provides the support they need.

Other topics addressed during this session include the following.

(a) How people are feeling physically and emotionally.

(b) An update on the current situation of people who have not been able to attend for a while due to health, treatment, transport, work or other reasons.

(c) Treatments and their responses to them.

(d) Clinical trials that members are taking part in.

(e) When scans are due/results pending.

(f) Satisfaction/dissatisfaction with aspects of care or treatment-comparing different NHS Trusts.

(g) General lack of support for people with secondary breast cancer.

(h) Appreciation of support from $\mathrm{BCH}$ and Breast Cancer Care, and other cancer charities.

\section{Talks by internal/external speakers}

An opportunity to experience different therapies such as Emotional Freedom Techniques, Breathing and Movement, Relaxation/Meditation during the day was available until February 2015.

This has been replaced by 1-hour talks by internal and external speakers, including breast surgeons, oncologists, psycho-oncologists and therapists, on a variety of topics, such as nutrition, pain management, fatigue, cancer treatment and mindfulness, chosen by participants.

\section{Healthy lunch}

In between the morning and afternoon sessions, a healthy vegan lunch is provided by volunteers at $\mathrm{BCH}$ to cater for all tastes, with dairy and wheat as optional extras. The content of the lunch is consistent with 'The Haven's Guide to Healthy Eating', developed by the charity based upon up-to-date high-quality research evidence $[8,9]$. 


\section{Afternoon session}

\section{A visualisation/relaxation session}

This 45-minute session, facilitated by the same therapist as the discussion session, is conducted in a large meeting room with reclining chairs, footrests and blankets to ensure that everyone taking part feels relaxed and comfortable.

The session, with quiet background music, starts with calm breathing, followed by a short full-body relaxation and a visualisation read by the therapist. The visualisation can be based on a variety of scenarios such as a country walk, a relaxing, floating experience, healing light, a mindfulness practice and walk on a beach or through forest. In the end, there is a short time for people to relax for a while listening to the music before they are invited to have a stretch and open their eyes when they are ready.

\section{Evaluation of secondary breast cancer support day}

Women with secondary breast cancer who attended monthly secondary breast cancer support days during the period February 2014-July 2018 were asked, at the end of the day, to complete a feedback form developed by BCH therapists to evaluate the helpfulness and suitability of the support day's programme. They were asked to rate the talks and sessions (very helpful, moderately helpful or not helpful), whether the day met their needs and expectations (yes/no) and, if no, to indicate what was missing, how they found the length of the day (too long, about right, too short), and to comment on which part(s) of the day they found most useful.

A total of 171 feedback forms were collected from 26 support days (completed feedback forms were not available for all support days conducted during this period).

\section{Data analysis}

Quantitative data from completed feedback forms were analysed using descriptive statistical analysis, giving a frequency analysis of responses (numbers and percentages) to each question.

Free text responses about the most useful part(s) of the support day were analysed by thematic analysis of the named sessions, accompanied by frequency analysis of the themes identified.

\section{Results}

\section{Personal introductions and discussion}

The majority of the 149 participants who attended/responded rated the session as very helpful $(N=125 ; 83.9 \%)$, with a further 19 (12.8\%) rating it as moderately helpful. Only five people (3.3\%) did not find the session helpful.

One participant commented that 'Meeting others and hearing their stories makes you feel not so alone' (P1).

\section{Talks by internal/external speakers}

The majority of the talks by internal/external speakers, which covered a wide range of different topics, were rated as being very helpful by the majority of participants, with the exception of the sleep and sound therapy sessions which were mostly reported as being moderately helpful by a small number of participants. The welfare, benefits and money advice and Ayurveda sessions had almost equal numbers of participants who rated them as very or moderately helpful. However, the numbers who attended were small $(n=7)$. With the exception of one person who attended the bioresonance talk, none of the participants found the talks by external speakers unhelpful (Table 1, Figure 1). 
Table 1. Rating the helpfulness of talks by internal/external speakers.

\begin{tabular}{|c|c|c|c|c|c|}
\hline Subject of talk & Very helpful & Moderately helpful & Not helpful & Didn't attend/ respond & Total \\
\hline Smoothie-making & 16 & & & & 16 \\
\hline Palliative care and role of hospice & 8 & & & & 8 \\
\hline Cancer-related fatigue & 7 & & & & 7 \\
\hline Organic skincare products & 5 & & & & 5 \\
\hline Shiatsu & 3 & & & & 3 \\
\hline Nutrition & 19 & 1 & & & 20 \\
\hline Medical herbalist & 7 & 1 & & & 8 \\
\hline Pain management & 5 & 1 & & & 6 \\
\hline Breast cancer & 4 & 1 & & & 5 \\
\hline Bioresonance & 7 & & 1 & 1 & 9 \\
\hline Exercise & 4 & 2 & & & 6 \\
\hline Reiki (healing) & 3 & 2 & & & 5 \\
\hline Harmony and balance & 20 & 7 & & 9 & 36 \\
\hline Mindfulness & 14 & 2 & & 10 & 26 \\
\hline Sleep & 2 & 5 & & & 7 \\
\hline Sound therapy & 2 & 3 & & & 5 \\
\hline Welfare, benefits and money advice & 4 & 3 & & & 7 \\
\hline Ayurveda & 4 & 3 & & & 7 \\
\hline Total & 134 & 31 & 1 & 20 & 186 \\
\hline
\end{tabular}

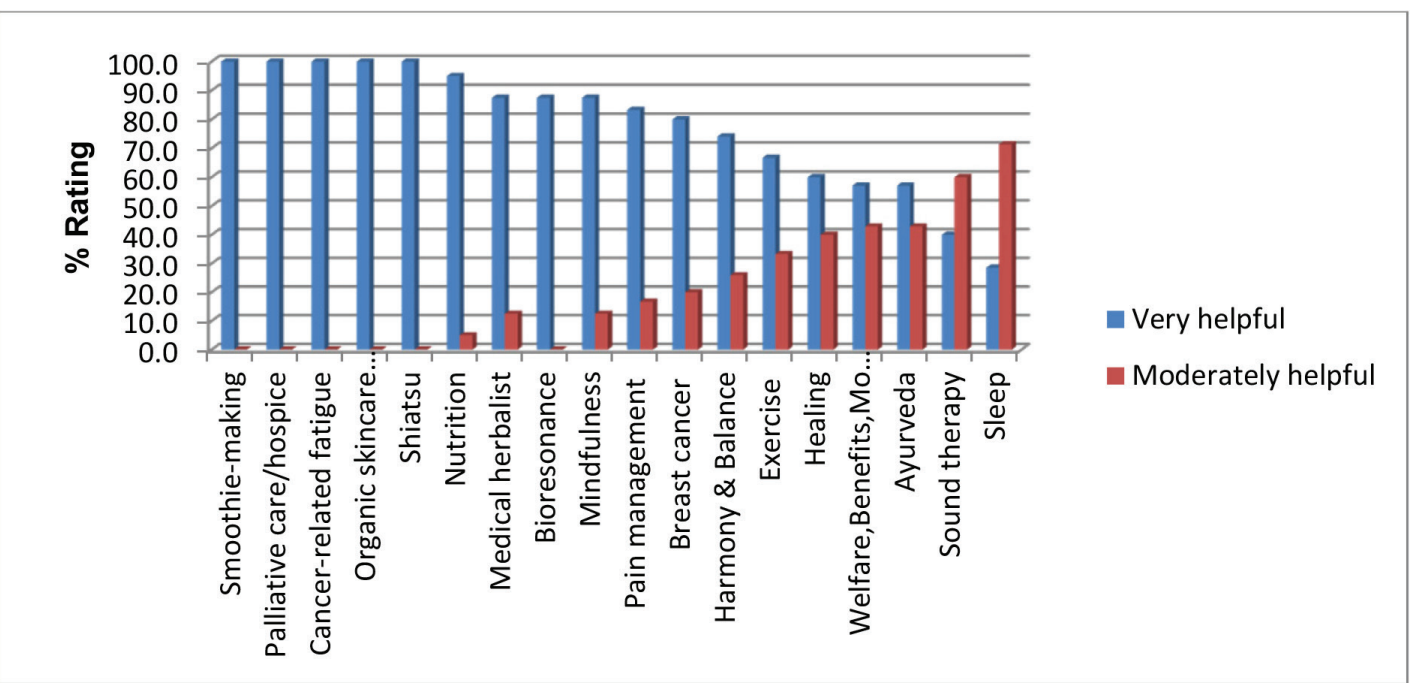

Figure 1. Percentage rating of talks by internal/external speakers. 
Table 2. Length of the day.

\begin{tabular}{|l|c|}
\hline \multicolumn{1}{|c|}{ Response } & Number (\%) \\
\hline Too long & $4(2.5)$ \\
\hline About right & $153(94.4)$ \\
\hline Too short & $5(3.1)$ \\
\hline Total & 162 \\
\hline
\end{tabular}

One participant made the following comment 'Masses of information I never knew. Made a visit to the hospice far less daunting' (P2).

\section{Visualisation/relaxation session}

Nearly all the participants $(N=102 ; 91.9 \%)$ who attended/responded found the afternoon session of visualisation/relaxation very helpful, whilst nine people (8.1\%) felt it was moderately helpful. None of the participants found the session unhelpful. As one participant stated 'I could do with an extra 15 mins on this session as it's so relaxing and helpful' (P3).

\section{Support day meets expectations and needs?}

All participants, except two, who answered the yes/no question $(N=159 ; 98.8 \%)$ agreed that the support day met their needs and expectations. One participant commented 'Yes-I was made very welcome. The structure of the session and topics were interesting' (P4).

\section{Length of the support day}

The majority of participants $(N=153 ; 94.4 \%)$ thought that the length of the day was about right (Table 2$)$.

\section{Most useful part(s) of the support day}

There were 204 responses to the question about the most useful part(s) of the day. (Some respondents gave more than one answer.)

The part of the day most frequently found to be useful by respondents was the opportunity to introduce themselves and talk and share information with others in a similar situation ( $N=72 ; 35.3 \%)$, followed by talks by internal/external speakers $(N=48 ; 23.5 \%)$ and the visualisation/ relaxation sessions $(N=43 ; 21.1 \%)$. There were only three negative comments: the talks could have been longer, lunchtime felt too long, and there was too much free time (Table 3 ).

\section{Any other comments to help improve the support day}

The most frequent responses were positive comments about the support day (well run, enjoyable, helpful, relaxing, informative, comforting, supportive, welcoming, invaluable day, very good structure, look forward to, feel better after) and appreciation of the support received $(N=58 / 87 ; 66.7 \%)$.

A longer Personal Introductions and Discussion session allowing more interaction with others was requested by six participants, and three others suggested that name labels would be helpful (this suggestion has now been acted upon and first name badges are provided). Other individual suggestions were made by 14 participants including help with lymphoedema, a discussion on how to honour a lost member, armchair exercise and help with dating for cancer patients. 
Table 3. Comments about the most useful part(s) of the day.

\begin{tabular}{|l|c|l|}
\hline \multicolumn{1}{|c|}{ Topics } & $\begin{array}{c}\text { Number of } \\
\text { responses }\end{array}$ & Participant quotes \\
\hline Introductions/group sharing session & 72 & $\begin{array}{l}\text { 'Meeting others in the same situation as myself'. } \\
\text { 'Listening to other ladies about their cancer and treatment and their feelings'. } \\
\text { 'An authentic discussion on loss of group members'. }\end{array}$ \\
\hline Information provided by internal/external speakers & 48 & $\begin{array}{l}\text { 'Discussing and learning about new treatments and what trials are on'. } \\
\text { Learnt that... 'Healthy food can be simple and easy to prepare-and tasty!' } \\
\text { 'Good to know about benefits of exercise'. } \\
\text { 'The (welfare and benefits) information was invaluable. I can claim for things that I had } \\
\text { no idea about'. }\end{array}$ \\
\hline Visualisation/relaxation/meditation & 43 & 'Relaxation is the best way to finish-leave floating'. \\
\hline Morning, afternoon or all day helpful & 26 & $\begin{array}{l}\text { 'I enjoyed the whole day and the different experiences. The day has given me a lift and } \\
\text { I have had a very positive experience from the day'. }\end{array}$ \\
\hline Therapies (offered up to February 2015) & 9 & 'The series on movement/breathing was excellent'. \\
\hline Lunch & 4 & The length for lunch is just right \\
\hline Environment & 2 & 'Lovely space for us to meet'. \\
\hline Total & 204 & \\
\hline
\end{tabular}

There were six negative comments: four people complained about a distracting noise outside the room during relaxation, one person felt that discussions were dominated by individuals and another found that the bioresonance session was unhelpful.

\section{Discussion}

People with secondary breast cancer say that often they are not getting the care and support they need to live well nor are their information needs being met [5]. The $\mathrm{BCH}$ support day at its centre in Yorkshire was specifically developed to provide a safe, welcoming environment in which emotional/psychological support is combined with an information component delivered by internal/external speakers to try and address these unmet needs.

Participants of the monthly support day for people with secondary breast cancer found it helpful, relaxing, informative, supportive and enjoyable. All except two felt it met their needs and expectations and the majority found the length of the day just right. They most frequently rated the time to talk to each other about themselves and their issues as the most useful part of the day, with nearly three-quarters of them rating it as very helpful.

New treatments for secondary breast cancer are prolonging the length of life for many [10], but their needs and concerns, particularly the long-term, life-altering impacts of the disease and its treatment, are poorly understood. The most prevalent, persistent and disabling symptoms they experience include depression, anxiety, sleep disturbance, pain and fatigue [11-14].

Improvement of some psychological symptoms has been reported for group psychological interventions such as mindfulness-based stress reduction, cognitive behavioural therapy and supportive-expressive therapy $[15,16]$. The latter two therapies also appear to be effective in improving survival at 12 months [16]. The Personal Introductions and Discussion session offered as part of the BCH support day is based on a similar approach to that of supportive-expressive group therapy. The latter focuses, via a facilitator, on fostering mutual support and helping people face and deal with their disease-related stress, and has been shown to help reduce distress in people with secondary breast cancer [17]. 
Participants of the support day particularly valued the discussion session, more frequently rating it as the most useful part of the day. This concurs with the findings of an evaluation of information and support interventions developed for patients with secondary breast cancer at the Christie Hospital in Manchester, which showed that meeting others in similar situations was the most frequently reported reason for attending the events [18]. Furthermore, some participants took the opportunity before the first session started and during the lunch break, to talk with others in the group unfacilitated and to keep in contact with each other via texts, phone calls and as part of a WhatsApp group, demonstrating the need for peer as well as professional support. Such interactions helped to reinforce the feeling that they were not alone in dealing with their diagnosis. As one participant commented 'A lovely positive group-felt very supported by the other women' (P5).

Dealing with the issue of the death of a member of the group was an important topic of discussion: feedback to the therapist about the way this was handled within the group discussion showed that it was addressed in a way that the majority of the group found appropriate. One participant commented 'Memory book great idea. I bought a candle for (name) to light each month until it is no more' (P6). A reduction in traumatic stress symptoms associated with such issues has also been reported using supportive-expressive group therapy in women with secondary breast cancer [17].

Findings from large international surveys of women with secondary breast cancer have revealed their expressed need for good, accurate, in-depth information about their disease, standard and emerging treatments, and ways of coping with side effects and symptoms [19,20]. This was reflected in the wide range of topics for talks by internal/external speakers chosen by the participants of the support day. The participants frequently found this informational part of the day very helpful, suggesting that at least some of their informational needs were

being met. As stated by one participant 'Very interesting and informative. Makes it easier to understand the different treatments and why NHS/ NICE/ etc restrictions' (P7).

The majority of the participants found the relaxation with visualisation (guided imagery) afternoon session very helpful. Relaxation and guided imagery, alone or in combination, have been demonstrated to be effective interventions to decrease the psychological impact (mood, anxiety and depression) as well as alleviate the adverse effects (nausea and vomiting) in breast cancer patients undergoing chemotherapy treatment [21-23]. Several of the participants commented on how much they enjoyed the relaxation session. One commented that 'The relaxation at the end is just perfect' (P8).

As far as we are aware, this is the first reported evaluation of a model of survivorship care developed specifically for people with secondary breast cancer. This approach would also be applicable and potentially beneficial for any breast cancer survivors as it is similar in content to other positively evaluated group support events offered at $\mathrm{BCH}[6,7]$. Further research is needed in a larger sample of patients to explore and identify those components that address their unmet needs most effectively.

\section{Conclusions}

Many people living with secondary breast cancer feel isolated and in need of specific support to improve their quality of life and to help with a variety of symptoms and side effects. BCH's monthly support days offer a safe, welcoming environment in which psychoeducational and social support tailored to address these unmet needs is provided. Evaluation of this model of survivorship care shows that such an approach can have a positive impact on people living with secondary breast cancer.

\section{Conflicts of interest}

Dr Barbara Baker and Dr Caroline Hoffman are employees of $\mathrm{BCH}$. Jean Marshall is a self-employed therapist and group facilitator who runs the $\mathrm{BCH}$ secondary breast cancer support days.

\section{Funding}

No external funding was received for this evaluation. 


\section{Acknowledgments}

The authors would like to thank the people with secondary breast cancer who took part in this BCH-support day evaluation.

\section{References}

1. Mehta RS, Barlow WE, and Albain KS, et al (2012) Combination anastrozole and fulvestrant in metastatic breast cancer N Engl J Med 367 435-444 https://doi.org/10.1056/NEJMoa1201622 PMID: 22853014 PMCID: 3951300

2. Maher J and McConnell H (2011) New pathways of care for cancer survivors: adding the numbers Br J Cancer 105 S5-S10 https://doi. org/10.1038/bjc.2011.417 PMID: 22048033 PMCID: 3251951

3. Cancer Research UK (2016) [https://www.cancerresearchuk.org/health-professional/cancer-statistics/statistics-by-cancer-type/breastcancer\#heading-Two] Date accessed: 10/12/19

4. Breast Cancer Now (2016) Breast cancer care report, September 2016: secondary breast cancer part two: who's counting? [https:// breastcancernow.org/get-involved/campaign-us/secondary]

5. Breast Cancer Now (2017) Breast cancer care report, October 2017: the case for change [https://breastcancernow.org/get-involved/ campaign-us/secondary]

6. Seers HE, Gale N, and Paterson C, et al (2009) Individualised and complex experiences of integrative cancer support care: combining qualitative and quantitative data Support Care Cancer 17(9) 1159-1167 https://doi.org/10.1007/s00520-008-0565-3 PMID: 19139927

7. Harrington JE, Baker BS, and Hoffman CJ (2012) Effect of an integrated support programme on the concerns and wellbeing of women with breast cancer: a national service evaluation Complement Ther Clin Pract 18(1) 10-15 https://doi.org/10.1016/j.ctcp.2011.05.002

8. WCRF/AICR Continuous Update Project Expert Report (2018) Diet, nutrition, physical activity and breast cancer survivors [dietandcancerreport.org] Date accessed: 21/03/19

9. Ruiz RB and Hernández PS (2014) Diet and cancer: risk factors and epidemiological evidence Maturitas 77 201-208

10. Turner NC, Slamon DJ, and Ro J, et al (2018) Overall survival with palbociclib and fulvestrant in advanced breast cancer N Engl J Med 379(20) 1926-1936 https://doi.org/10.1056/NEJMoa1810527 PMID: 30345905

11. Aranda S, Schofield P, and Weih L, et al (2005) Mapping the quality of life and unmet needs of urban women with metastatic breast cancer Eur J Cancer Care 14 211-222 https://doi.org/10.1111/j.1365-2354.2005.00541.x

12. Grabsch B, Clarke DM, and Love A, et al (2006) Psychological morbidity and quality of life in women with advanced breast cancer: a cross-sectional survey Palliat Support Care 4 47-56 https://doi.org/10.1017/S1478951506060068 PMID: 16889323

13. Koopman C, Nouriani B, and Erickson V, et al (2002) Sleep disturbances in women with metastatic breast cancer Breast J 8 362-370 https://doi.org/10.1046/j.1524-4741.2002.08606.x PMID: 12390359

14. Palesh OG, Collie K, and Batiuchpk D, et al (2007) A longitudinal study of depression, pain and stress as predictors of sleep disturbance among women with metastatic breast cancer Biol Psychol 75 37-44 https://doi.org/10.1016/j.biopsycho.2006.11.002

15. Eyles C, Leydon GM, and Hoffman CJ, et al (2015) Mindfulness for the self-management of fatigue, anxiety and depression in women with metastatic breast cancer: a mixed methods feasibility study Integr CancerTher 14(1) 42-56 https://doi.org/10.1177/1534735414546567 PMCID: 4390604

16. Mustafa M, Carson-Stevens A, and Gillespie D, et al (2013) Psychological interventions for women with metastatic breast cancer Cochrane Database Syst Rev (6) https://doi.org/10.1002/14651858.CD004253.pub4

17. Classen C, Butler LD, and Koopman C, et al (2001) Supportive-expressive group therapy and distress in patients with metastatic breast cancer Arch Gen Psychiatry 58 494-501 https://doi.org/10.1001/archpsyc.58.5.494 PMID: 11343530 
18. Gaskell C, Foy S, and Fox R, et al (2017) Evaluating health and well-being interventions for patients with secondary breast cancer Cancer Nurs Pract 16(8) 26-33 https://doi.org/10.7748/cnp.2017.e1457

19. Mayer M (2010) Lessons learned from the metastatic breast cancer community Seminars Oncology Nursing 26(3) 195-202

20. Harding V, Ashfar M, and Krell J, et al (2013) 'Being there' for women with metastatic breast cancer: a pan-European patient survey $\mathrm{Br}$ J Cancer 109 1543-1548 https://doi.org/10.1038/bjc.2013.492 PMID: 24002595 PMCID: 3777001

21. Hosseini M, Tirgari B, and Forouzi MA, et al (2016) Guided imagery effects on chemotherapy induced nausea and vomiting in Iranian breast cancer patients Complement Ther Clin Pract 25 8-12 https://doi.org/10.1016/j.ctcp.2016.07.002 PMID: 27863614

22. Chen SF, Wang HH, and Yang HY, et al (2015) Effect of relaxation with guided imagery on the physical and psychological symptoms of breast cancer patients undergoing chemotherapy Iran Red Crescent Med J 17(11) e31277 https://doi.org/10.5812/ircmj.31277

23. Kapogiannis A, Tsoli S, and Chrousos G (2018) Investigating the effects of the progressive muscle relaxation-guided imagery combination on patients with cancer receiving chemotherapy treatment: a systematic review of randomized controlled trials Explore (NY) 14(2) 137-143 https://doi.org/10.1016/j.explore.2017.10.008 